\title{
Delayed Sternal Closure in Congenital Heart Surgery: A Risk-Benefit Analysis
}

\author{
Ahmed Abdelrahman Elassal, MD, ,,2 Osama Saber Eldib, MD, ${ }^{2}$ Ahmed Mohamed Dohain, MD,,$^{3,4}$ \\ Gaser Abdelmohsen Abdelmohsen, MD, ${ }^{3,4}$ Ahmed Hassan Abdella, MSC, ${ }^{1,5}$ Osman Osama Al-Radi, FRCSC ${ }^{1}$ \\ ${ }^{1}$ Department of Surgery, King Abdulaziz University Hospital, Jeddah, Saudi Arabia; ${ }^{2}$ Department of Cardiothoracic Surgery, Faculty \\ of Medicine, Zagazig University, Egypt; ${ }^{3}$ Department of Pediatrics, Cairo University, Cardiology Division, Egypt; ${ }^{4}$ Department of \\ Pediatrics, King Abdulaziz University Hospital, Jeddah, Saudi Arabia; ${ }^{5}$ Alahrar Teaching Hospital, Zagazig, Egypt
}

\section{ABSTRACT}

Background: Delayed sternal closure commonly is used after pediatric cardiac surgery. Its benefits include relieving cardiac compression and stabilizing postoperative critically ill patients.

Methods: We retrospectively reviewed the records of 72 patients, who had undergone delayed sternal closure, among 1,254 patients operated for congenital heart diseases. Indications of delayed sternal closure, perioperative hemodynamic and metabolic status, postoperative infection, and mortality were reported.

Results: Transposition of great arteries was the most common preoperative cardiac pathology (26.3\%). Bleeding and hemodynamic instability were the most frequent indications for delayed sternal closure, representing $38.8 \%$ and $34.7 \%$, respectively. The mean duration of open chest was 3.45 days \pm 1.46 days. The mean duration of ICU stay was 20.95 days \pm 20.06 days. Two patients had deep sternal wound infection. Sepsis was found in 39 patients (54.1\%), and the most common causative organism was coagulase negative $(30.5 \%)$. ICU stay was a significant risk factor for sepsis $(P=.003)$; duration of open sternum, period of mechanical ventilation $(\mathrm{MV})$, and total hospital stay were not statistically significant risk factors. Sternal closure time (SCT) was affected by period of hemodynamic instability $(P=.036)$. Bypass time, clamping time, and nonsurgical bleeding did not significantly affect SCT. The mortality rate was $15.2 \%(\mathrm{~N}=11)$.

Conclusion: Delayed sternal closure is a simple and effective technique that could prevent postoperative cardiac compression in hemodynamic instability states after pediatric cardiac operations.

\section{INTRODUCTION}

Delayed sternal closure is a therapeutic modality to manage hemodynamic instability resulting from cardiac compression by sternal closure.

Received March 18, 2019; received in revised form fuly 2, 2019; accepted fuly 24, 2019.

Correspondence: Abmed Abdelrahman Elassal, Department of Surgery, King Abdulaziz University Hospital, Jeddah, Saudi Arabia; (e-mail: samalassal1434@gmail.com).

\section{MATERIALS AND METHODS}

We retrospectively reviewed records of 72 patients, who had undergone delayed sternal closure, among 1,254 patients operated for congenital heart diseases at King Abdul Aziz University Hospital, from 2013 to 2018. Preoperative cardiac pathology is shown in Table 1.

Recorded were indication of DSC, time to sternal closure, and pre- and post-closure cardiopulmonary and metabolic status, including hemodynamic state and lactate level. Other variables, including ventilator support duration, mean intensive care unit (ICU) and hospital stay times, mortality, wound infections, and bloodstream infections were studied.

For myocardial protection, we used antegrade cold blood cardioplegia without epicardial ice slush. The initial dose was $30 \mathrm{ml} / \mathrm{kg}$ and subsequent doses were $20 \mathrm{ml} / \mathrm{kg}$ with intervals of 20 minutes. Systemic temperature was drafted to $30^{\circ} \mathrm{C}$ to $32^{\circ} \mathrm{C}$. In deep hypothermic circulatory arrest, the patient was cooled to $18^{\circ} \mathrm{C}$ with an ice pack on the head. All cases routinely were ultrafiltrated, during $\mathrm{CPB}$ with the exception of one case of coarctation repair.

The decision to leave the sternum open was based on hemodynamic state, lactate level, presence of myocardial edema, non-surgical bleeding, and conduction of extracorporeal membrane oxygenation (ECMO).

Sterna were kept open without the use of a retractor. Skin was not sutured. We closed wounds with a latex membrane (Esmark bandage). If there was a marked disproportion between cardiac size and thoracic cavity, we fixed a piece of bypass circuit tube between the two sternal bars to keep steadily open the chest. Dressing was changed daily in ICU.

Regarding antibiotic prophylaxis, we used cefazolin and vancomysin then according to culture. Postoperatively, we used Fentanyl at $1-4 \mu / \mathrm{kg} / \mathrm{hr}$ for sedation and Pancuronium at $0.25-0.75 \mu / \mathrm{kg} / \mathrm{m}$ as a muscle relaxant. When hemodynamic and respiratory parameters improved, lactate level lowered and negative fluid balance settled, a trial of sternal closure was attempted. We closed the sternum by interrupted simple stainless steel wires (size 1 to 4 , according to weight). Muscle, subcutaneous tissue and skin were closed as one layer by interrupted mattress 3/0-4/0 polyprolene sutures. 
Table 1. Cardiac Pathology

\begin{tabular}{ll}
\hline VSD & 2 \\
IAA & 5 \\
Tetralogy of Fallot & 7 \\
Truncus arteriosus & 7 \\
Tricuspid atresia & 1 \\
LVOT tunnel type & 1 \\
TGA & 19 \\
Mitral insufficiency & 1 \\
Coarctation & 5 \\
Univentricular heart & 2 \\
Mitral atresia & 2 \\
TAPVD & 3 \\
DORV & 3 \\
Hypoplastic left heart syndrome & 3 \\
Pulmonary atresia & 5 \\
DOLV & 1 \\
AVSD & 6 \\
\end{tabular}

\section{RESULTS}

Seventy-two patients with DSC were studied. All were left open at the end of the operation, with no patients opened in ICU. We had $30(41.6 \%)$ females and $42(58.3 \%)$ males. The mean age was $317.14 \pm 753.28$ (4-4256 days). There were no patients with previous sternotomy. TGA was the most common preoperative cardiac pathology (26.3\%). Mean bypass time was 90.4 minutes \pm 50.5 minutes (15-319 minutes) and mean clamping time was 55.77 minutes \pm 38.01 minutes (6-215 minutes). Total circulatory arrest was conducted in 25 patients, and the mean duration was 22.72 minutes \pm 12.98 minutes (3-51 minutes). Indications of leaving the sternum open in OR are summarized in Table 2. We used ECMO in 5 patients. Peritoneal dialysis was performed in 38 patients $(52.7 \%)$. Echocardiography routinely was done in ICU on the first postoperative day and immediately before closure. It showed poor cardiac function in $73.36 \%$ of patients on the first postoperative day. The mean duration of open chest was 3.45 days \pm 1.46 days (1-7 days). The mean period of mechanical ventilation was 9.25 days \pm 8.37 days (3-56 days). The mean duration of ICU stay was 20.95 days \pm 20.06 days (4-120 days) and total hospital stay was 26.48 days \pm 22.67 days (1-124 days). Sepsis was found in 39 patients $(54.1 \%)$, and the most common causative organisms were coagulase negative (30.5\%), klebsiella pneumonia (16.6\%), and pseudomonas (13.8\%).

Table 4 shows postoperative infection data. Two patients had deep sternal wound infection; one of them died from septic shock. We had 11 cases $(15.2 \%)$ of mortality. Five patients were supported by ECMO. Causes of death are shown in Table 3.

Statistical regression showed ICU stay as a significant risk factor for sepsis $(P=.003)$, while duration of sternal closure,
Table 2. Indications of Open Chest

\begin{tabular}{ll}
\hline Indication & Number \\
\hline Non-surgical bleeding & 28 \\
Cardiac edema & 12 \\
Hemodynamic instability & 25 \\
High inotropes & 16 \\
Respiratory (low saturation) & 7 \\
Long bypass time & 8 \\
ECMO & 5
\end{tabular}

period of MV, and total hospital stay were not statistically significant risk factors. Sternal closure time was affected by period of hemodynamic instability $(P=.036)$. Bypass time, clamping time, and nonsurgical bleeding did not significantly affect SCT.

\section{DISCUSSION}

Cardiomediastinal disproportion was first described by Riahi and colleagues in 1975 [Riahi 1975]. Factors accounting for this problem include myocardial edema from reperfusion injury and cardiac manipulation, bleeding, arrhythmias, and ventricular dysfunction. This condition often is associated with poor myocardial protection and prolonged bypass time [Das 2011]. In the surgical era of shifting from palliative to corrective operations, DSC was more common. Furnary and colleagues reported the beneficial effect of DSC on hemodynamics. Cardiac index increased up to 59\% and systolic blood pressure rose up to $18 \%$ with the opening of the sternum [Yasa 2010].

It has become an acceptable practice in pediatric centers to leave the sternum open electively in OR especially after long bypass time or after Norwood procedures [Johnson 2010]. All patients included in our study electively were left open. Our decision was based on hemodynamic parameters, TEE, and lactate level. TGA and HLHS were the most common cardiac pathology reported in most of series of DSC [Iyer 1997; Riphagen 2005; Tabbutt 1997].

In our study, TGA was the most common diagnosis accounting for $26.3 \%$ of our cases. Some investigators [Das 2011; Johnson 2010] limit their studies about DSC to patients with HLHS, in an effort to decrease variability. We included 5 patients with HLHS in our series. One of patients died because of post-ECMO multiorgan failure. Bleeding and hemodynamic instability represent the most frequent indications for DSC [Hurtado 2018]. They accounted for 38.8\% and $34.7 \%$ of our indications, respectively. When to close the sternum still is debatable. Some centers delay closure for at least 3 days [Tabbutt 1997].

Riphagen et al emphasized the feasibility of early DSC within 24 hours without hemodynamic, respiratory, or metabolic compromise. The advantages of their policy are lower 
Table 3. Causes of Death

\begin{tabular}{lcc}
\hline & ECMO Used & ECMO Not Used \\
\hline Cause of death & No. & No. \\
Septic shock & 1 & 2 \\
Low cardiac output & 2 & 0 \\
Multisystem organ failure & 1 & 0 \\
DIC & 1 & 1 \\
Pulmonary hemorrhage & 0 & 1 \\
Respiratory failure & 0 & 2 \\
Total & 5 & 6
\end{tabular}

nosocomial infections and ventilator associated complications [Riphagen 2005].

However, this aggressive approach should be taken with caution since premature closure of the sternum with repeat DSC has more adverse effects than prolonging the period of DSC [Harder 2013].

We decide for closure when (1) the patient becomes hemodynamically stable; (2) no malignant arrhythmias are present; (3) arterial blood gases are acceptable; (4) negative fluid balance state; (5) lactate level decreases; and (6) echocardiography shows improved cardiac function and no significant residual shunt across septae or significant gradient across LVOT, RVOT, or valves. Mean closure time in our series was 3.45 days \pm 1.46 days. The only factor that proved to affect sternal closure time in our study was the period of hemodynamic instability. Various methods have been described for sternal closure. These include primary skin closure, use of sternal retractor, silicone sheet, mediastinal packing, and stenting the sternum by a piece of bypass circuit tube [Iyer 1997]. Staged closure using a binder clip was described by Fuchigami et al [Fuchigami 2016]. We usually use latex membrane (Esmark) for closure. This way, the mediastinum is isolated from the atmosphere.

With any cases of marked cardiac edema, we stent the sternum with a piece of bypass circuit tube. Complications of DSC include sternal wound infection, mediastinitis, and sepsis. We had 2 patients $(2.7 \%)$ who developed deep sternal wound infection. The reported incidence of surgical site infection in the pediatric population after DSC ranges from $0 \%$ to $28 \%$. Woodward et al reported $1.53 \%$ incidences of mediastinitis based on a multicenter study that included 8,774 patients [Woodward 2011]. They stated that DSC was not associated with increased risk of mediastinitis. We think that elective opening and closing of the sternum in OR together with a short period of open chest ( 3.45 days \pm 1.46 days in our study) explained our low incidence of SSI. We found that duration of ICU stay was a significant risk factor for sepsis. This finding is similar to that previously reported by Johnson et al who evaluated 1,283 patients operated in 45 centers for Stage 1 palliation for HLHS. DSC was performed in $74 \%$. They stated that longer length of stay was associated with a higher rate of infection [Johnson 2010]. On the other hand, sternal closure time did not significantly influence our rate of deep sternal wound infection. This is an interesting point in our results. We confirm the previous studies in this regard [Erek 2012; Tabbutt 1997; Woodward 2011]. Many authors reported higher incidence of infection with a longer period of open chest [Anderson 2002; Furnary 1992; Nelsonm 2016]. We agree with Harder et al [Harder 2013] that repeat DSC rather than prolonged period of open chest influences the rate of infection. This raises the importance of avoiding premature closure of the sternum.

Blood stream infection increases four-fold after DSC [Das 2011]. For more information, look to Table 5. Özker et al reported prolonged antibiotic use due to postoperative infection in 52.6\% of patients [Özker 2012]. Sepsis was found in 39 of our patients $(54.1 \%)$. The most common organism isolated in our patients was Gram negative, which is in agreement with literature [Pollock 1990; Tabbutt 1997; Woodward 2011].

Our mortality rate was $15.2 \%$ (11 patients), which is comparable to the range of $11 \%$ to $36 \%$ reported in literature [Alexi 1995; Hurtado 2018; Özker 2012]. For more information, look to Table 5. Özker et al and Hurtado et al reported mortality of $22 \%$ and $34.2 \%$, resepectively [Hurtado 2018; Özker 2012].

Higher rates of infection and mortality were reported if the sternum was opened in CICU, when compared with those kept open electively in OR [Pollock 1990; Samir 2002]. This highlights the importance of predicting patients in need of DSC at the end of an operation. Samir et al analyzed risk factors that may predict the need for DSC among 312 neonates, who underwent open heart surgery. They found that an age of less than 7 days, diagnosis of IAA or TAPVD, aortic clamping time of more than 98 minutes and bypass time exceeding 185 minutes, and central venous saturation after bypass lower than $51 \%$ are significant risk factors. Other factors, including prematurity, preoperative inotropic or ventilator support, circulatory arrest, type of cardioplegia, and use of ultrafiltration were not statistically significant risk factors [Samir 2002].

Edwards and Baker found the rate of infection is increased with long bypass time, long duration of low COP state, and excessive bleeding [Edwards 1983]. We found that ICU stay was the only significant factor that influenced the rate of infection. Nelson-McMillan analyzed STS congenital heart surgery database of 6,127 operations with sternum left open in 100 centers. They reported infection rate $18.7 \%$ in patients with the sternum left open compared with $6.6 \%$ in patients without this in the same age and procedural groups. DSC in ICU location was not associated with increased risk of infection. Within the first few days, day-to-day increments in risk of infection were small [Nelsonm 2016]. Harder et al found that use of ECMO and multiple periods of DSC were independent risk factors of SSI [Harder 2013]. We used ECMO in 10 patients. Three of them developed sepsis and 5 died. Mean duration of open chest in the remaining 5 survivors was 5.25 days.

\section{CONCLUSION}

Delayed sternal closure is a simple and effective method that could relieve cardiac compression in a state of hemodynamic 
Table 4. Postoperative infection data

\begin{tabular}{|c|c|c|c|c|}
\hline 1 & VSD-coarctation & Blood, pleural fluid & coagulase -ve staph & \\
\hline 3 & Mitral insufficiency & Respiratory & Gram -ve bacilli & \\
\hline 4 & TGA & Respiratory & Enterobacter & \\
\hline 6 & Coarctation & Sputum & klebsella pneumonia & \\
\hline 7 & Truncus arteriosus & Tracheal aspirate & MRSA & \\
\hline 8 & Coarctation & Bronchoalveolar lavage & $\begin{array}{l}\text { Pseudomonas argunosa, sphengomonas paucimo- } \\
\text { bilis }\end{array}$ & \\
\hline 9 & DORV & Peritoneal fluid & coagulase -ve staph & Died \\
\hline 12 & Pulmonary atresia VSD (PA/VSD) & Tracheal aspirate & Pseudomonas argunosa & \\
\hline 13 & TGA & Tracheal aspirate & Klebsiella pneumonia & \\
\hline 14 & TGA & Nasopharyngeal aspirate & Klebsiella pneumonia & \\
\hline 15 & TAPVD-intracardiac & Tracheal aspirate & Klebsiella pneumonia & \\
\hline 16 & Univentricular heart LV type & Blood & Coagulase negative staph & \\
\hline 17 & Tetralogy of Fallot & $\begin{array}{l}\text { Urine Peritoneal fluid } \\
\text { coagulase negative staph }\end{array}$ & Enterococcus fecalis, E.coli & Died \\
\hline 18 & Tetralogy of Fallot & $\begin{array}{l}\text { Sputum blood staph } \\
\text { epidermdis }\end{array}$ & Yeast, acinetobacter baumannii & \\
\hline 25 & DORV & Urine & klebseilla pneumonia & \\
\hline 26 & Truncus arteriosus & Tracheal aspirate & H. influenza & \\
\hline 27 & TGA & Tracheal aspirate & $\begin{array}{c}\text { stenotrophomonas maltophilia PSEDOMONAS } \\
\text { ARGUNOSA }\end{array}$ & \\
\hline 28 & Pulmonary atresia IVS (PA/IVS) & Tracheal aspirate & MRSA & \\
\hline 29 & TOF & Tracheal aspirate & Pseudomonas & \\
\hline 30 & DOLV & Blood & coagulase -ve staph & \\
\hline 31 & TOF & Tracheal aspirate & Enterobacter aerginosa & \\
\hline 32 & AVSD-Complete & $\begin{array}{l}\text { Nasopharyngeal swab } \\
\text { blood }\end{array}$ & $\begin{array}{l}\text { MORAXELLA CATARRALIS chyreseobactrium } \\
\text { menengiosepticum }\end{array}$ & \\
\hline 33 & TGA & Blood & Coagulase -ve Staph & \\
\hline 34 & Interrupted aortic arch (IAA) & Wound & Pseudomonas & \\
\hline 35 & Interrupted aortic arch (IAA) & Tracheal aspirate & K. pneumonia & Died \\
\hline 36 & HLHS & Tracheal aspirate & ENTEROBACTER CLOACAE) & \\
\hline
\end{tabular}


Table 5. Incidence, sites of infection and mortality reported in pediatric series are shown

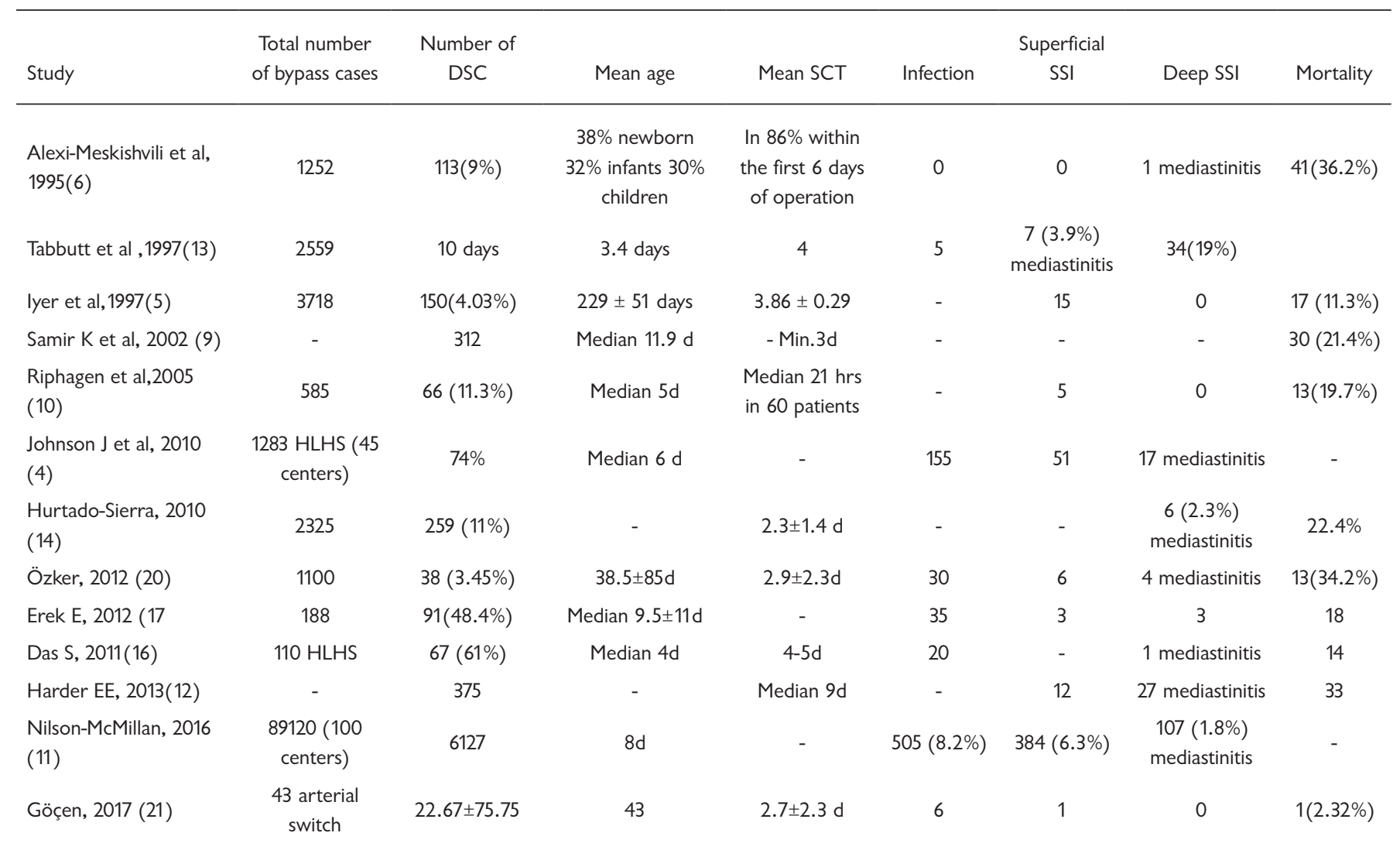

instability after congenital heart surgery. A low incidence of surgical site infection is a favorable outcome to adopt it as a therapeutic modality.

\section{REFERENCES}

Alexi M V, Weng Y, Uhlemann F, Lange PE, Hetzer R. 1995. Prolonged open sternotomy after pediatric open heart operation: experience with 113 patients. Ann Thorac Surg 59:379-83.

Anderson CA, Filsoufi F, Aklog L, Farivar RS, Byrne JG, Adams DH. 2002. Liberal use of delayed sternal closure for postcardiotomy hemodynamic instability. AnnThorac Surg. 73:1484-8.

Das S, Rubio A, Simsic JM, et al. 2011. Bloodstream infections increased after delayed sternal closure: cause or coincidence. Ann Thorac Surg 91:793-8.

Edwards MS, Baker CJ. 1983. Median sternotomy wound infections in children. Pediatr Infect Dis 2:105-9.

Erek E, Yalcinbas YK, Turkekul Y, Saygili A, Ulukol A, Sarioglu CT. 2012. Indications and Risks of Delayed Sternal Closure After Open Heart Surgery in Neonates and Early Infants. World Journal for Pediatric and Congenital Heart Surgery 3(2) 229-235.

Fuchigami T, Nishioka M, Akashige T, Higa S, Nagata N. 2016. Staged delayed sternal closure using a binder clip after pediatric cardiac surgery. J Card Surg 31:464-466).

Furnary AP, Magovern JA, Simpson KA, Magovern GJ. 1992. Prolonged open sternotomy and delayed sternal closure after cardiac operations. Ann Thorac Surg 54:233-239.

Göçen U. 2017. Delayed sternal closure after arterial switch operations: a single center experience. Cukurova Med J 42(3):540-545.

Harder EE, Gaies MG, Yu S, et al. 2013. Risk factors for surgical site infection in pediatric cardiac surgery patients undergoing delayed sternal closure. J Thorac Cardiovasc Surg 146:326-33.

Hurtado SD, Calderón CJ, Curi-Curi P et al. 2018. Outcomes of Delayed Sternal Closure in Pediatric Heart Surgery: Single-Center Experience. BioMed Research International, vol. 2018, Article ID 3742362, 6 pages.

Iyer RS, Jacobs JP, de Leval MR et al. 1997. Outcomes after delayed sternal closure in pediatric heart operations: A 10-Year Experience. Ann Thorac Surg 63:489-91.5.

Johnson JN, Jaggers J,Li S, et al. 2010. Center Variation and Outcomes Associated with Delayed Sternal Closure Following Stage 1 Palliation for Hypoplastic Left Heart Syndrome. Thorac Cardiovasc Surg. May; 139(5): 1205-1210.

Nelsonm MK, Hornik CP, He X, et al. 2016. Delayed Sternal Closure in Infant Heart Surgery-The Importance of Where and When: An Analysis of the STS Congenital Heart Surgery Database. Ann Thorac Surg 102:1565-72.

Özker E, Sarita B, Vuran C, Yörüker U, Ulugö H, and Türköz R. 2012. Delayed sternal closure after pediatric cardiac operations; single center experience: a retrospective study. Journal of Cardiothoracic Surgery $7: 102$. 
Pollock EM, Ford JL, Rebeyka I, et al. 1990. Early nosocomial infections in pediatric cardiovascular surgery patients. Crit Care Med 18:378-84.

Riahi M, Tomatis LA, Schlosser RJ, Bertolozzi E, Johnston DW. 1975. Cardiac compression due to closure of the median sternotomy in openheart surgery. Chest 67:113-114.

Riphagen S, McDougall M, Tibby SM, et al. 2005. "Early" delayed sternal closure following pediatric cardiac surgery. Ann Thorac Surg 80:678-85.

Samir K, Riberi A, Ghez O, et al. 2002. Delayed sternal closure:a lifesaving measure in neonatal open heart surgery; could it be predictable.
European Journal of Cardio-thoracic Surgery 21 787-793.

Tabbutt S., Duncan BW, McLaughlin D, Wessel DL, JonasRA. Laussen PC. 1997. Delayed sternal closure after cardiac operations in a pediatric population. J Thorac Cardiovasc Surg 113:886-893.

Woodward CS, Son M, Calhoon J, Michalek J, Husain SA. 2011. Sternal wound infections in pediatric congenital cardiac surgery: a survey of incidence and preventative practice. Ann Thorac Surg. 91:799-804.

Yasa H, Lafc1 BB, Y1lık L, et al. 2010. Delayed sternal closure: an effective procedure for life-saving in open heart surgery. Anadolu Kardiyol Derg 10:163-167. 